\title{
ANALISIS IMPLEMENTASI CORPORATE SOCIAL RESPONSIBILITY (CSR) DALAM PEMBERDAYAAN MASYARAKAT PADA PT. PERKEBUNAN NUSANTARA IV SOSA DITINJAU DARI PERSPEKTIF EKONOMI ISLAM
}

\author{
Aminah Lubis, Saparuddin Siregar, and Isnaini Harahap \\ Program Studi Ekonomi Islam Pascasarjana \\ Universitas Islam Negeri Sumatera Utara Medan \\ email: aminahlubis21@yahoo.com
}

\begin{abstract}
This study aims to analyze in depth about: 1) The Partnership and Community Development program of PT. Perkebunan Nusantara IV Sosa, 2) The Implementation of Corporate Social Responsibility (CSR) PT. Perkebunan Nusantara IV Sosa in Community Empowerment, and 3) Review of Shariah Enterprise Theory (SET) to the Corporate Social Responsibility Program (CSR) at PT. Perkebunan Nusantara IV Sosa. This research is a field research with descriptive in qualitative research-inductive. The subjects were community and employees of PTPN IV Sosa. The primary data obtained through interviews with community and employee PTPN IV Sosa. The results showed that the Corporate Social Responsibility Program (CSR) PTPN IV-Sosa has implemented: (1) The provision of venture capital loan fund, grants; (2) Education (providing scholarships and improve school buildings); (3) Spiritual (repair houses of worship); (4) Infrastructure or public facilities (repairing roads and help provide school equipment); (5) The health sector (provision of funds for the provision of basic needs of natural disasters, drug, mass circumcision); and (6) Nature conservation (reforestation). Implementation of CSR programs PTPN IV Sosa channeled properly, for the partners held training and as expected by the public. Loking from the purposes, the implementation of the Enterprise Theory Shariah of the Corporate Social Responsibility (CSR) PTPN IV-Sosa has been in accordance with the principle of fair share, maslahah and rahmatan lil'alamin.

Keywords: Corporate Social Responsibility (CSR), Community Empowerment, and Shariah Enterprise Theory (SET).
\end{abstract}


2 | TAZKIR: Jurnal Penelitian Ilmu-ilmu Sosial dan Keislaman

Vol. 03 No. 1 Juni 2017

\begin{abstract}
Abstrak
Penelitian ini bertujuan untuk menganalisis secara mendalam tentang: 1) Program Kemitraan dan Bina Lingkungan PT. Perkebunan Nusantara IV Sosa, 2) Implementasi Program Corporate Social Responsibility (CSR) PT. Perkebunan Nusantara IV Sosa dalam Pemberdayaan Masyarakat, dan 3) Tinjauan Shariah Enterprise Theory (SET) terhadap Program Corporate Social Responsibility (CSR) pada PT. Perkebunan Nusantara IV Sosa. Penelitian ini merupakan penelitian lapangan (field research) dengan jenis penelitian kualitatif deskriptifinduktif. Subjek penelitian ini adalah masyarakat beserta karyawan PTPN IV Sosa. Data primer diperoleh melalui wawancara dengan masyarakat beserta karyawan PTPN IV Sosa. Hasil penelitian menunjukkan bahwa Program Corporate Social Responsibility (CSR) PTPN IV-Sosa yang dilaksanakan adalah (1) Pemberian dana pinjaman modal usaha, dana hibah, (2) Pendidikan (memberikan bantuan beasiswa dan memperbaiki gedung-gedung sekolah). (3) Kerohanian (perbaikan rumah ibadah). (4) Infrastruktur atau sarana umum (perbaikan jalan, membantu pengadaan peralatan Sekolah). (5) Sektor kesehatan (pemberian bantuan dana untuk pemberian sembako bencana alam, obat-obatan, sunatan massal) (6) Pelestarian alam (penghijauan). Implementasi program CSR PTPN IV Sosa tersalurkan dengan baik, bagi mitra binaan diadakan pelatihan dan sesuai yang diharapkan masyarakat. Tinjauan Shariah Enterprise Theory terhadap pelaksanaan program Corporate Social Responsibility (CSR) PTPN IV-Sosa jika dilihat dari segi tujuan, bahwa program ini telah sesuai dengan prinsip berbagi Adil, Mașlahah dan Rahmatan lil'alamìn.
\end{abstract}

Kata Kunci : Corporate Social Responsibility (CSR), Pemberdayaan Masyarakat, Shariah Enterprise Theory (SET).

\title{
PENDAHULUAN
}

Perusahaan sebagai salah satu aktor ekonomi dalam satu wilayah, baik itu wilayah desa, kecamatan, kabupaten, provinsi dan negara dituntut untuk menghasilkan profit maksimal. Namun prinsip bahwa perusahaan hanya berorientasi pada keuntungan sudah mulai ditinggalkan. Perusahaan harus juga memiliki tanggung jawab sosial sehubungan dengan keberadaannya ditengahtengah lingkungan masyarakat. ${ }^{1}$ Tanggungjawab perusahaan itu diantaranya

${ }^{1}$ Ismail sholihin, Coporate Social Responsibility, (Jakarta: kencana, 2010), hal. 12 
adalah ikut andil dalam mensejahterahkan ekonomi masyarakat melaui program kemitraan dan bina lingkungan. Tanggungjawab sosial perusahaan terhadap masyarakat ini disebut dengan Corparate Social Responsibility (CSR).

Corporate Social Responsibility (CSR) adalah komitmen perusahaan atau dunia bisnis untuk berkontribusi dalam pengembangan ekonomi yang berkelanjutan dengan memperhatikan tanggung jawab sosial perusahaan dan menitikberatkan pada keseimbangan antara perhatian terhadap aspek ekonomis, sosial, dan lingkungan. ${ }^{2}$ Praktek kedermawanaan sosial perusahaan dewasa ini mengalami perkembangan pesat sejalan dengan perkembangannya konsep Corporate Social Responsibility. Hal terkait dengan mandat dunia untuk tidak semata-mata mencari keuntungan, tetapi harus pula bersikap etis dan berperan dalam penciptaan investasi sosial. ${ }^{3}$

Banyak perusahaan yang melaksanakan kegiatan Corporate Social Responsibility (CSR) atau tanggung jawab sosial perusahaan yang dikemas dengan sedemikian rupa dan tidak hanya berupa sumbangan material tetapi bersifat memberdayakan masyarakat agar masyarakat dapat berdiri sendiri dapat mengembangkan keterampilan dan keahlian yang dimilikinya dengan berbagai macam proram CSR yang dikhusukan kepada masyarakat agar terciptanya masyarakat yang sejahtera dan mengurangi kemiskinan.

Jika dilihat dalam perspektif Islam, CSR sebenarnya merupakan konsekuensi inhern dari ajaran Islam. Tujuan dari syariat Islam (Maqașid al syari'ah) adalah mașlahah sehingga bisnis adalah upaya untuk menciptakan mașlahah, bukan sekedar mencari keuntungan. ${ }^{4}$ Bisnis dalam Islam memiliki posisi yang sangat mulia sekaligus strategis karena bukan sekedar diperbolehkan di dalam Islam, melainkan justru diperintahkan oleh Allah dalam Al-Qur'an. ${ }^{5}$

Aktivitas pengungkapan CSR perusahaan yang memiliki nilai-nilai agama dipengaruhi oleh beberapa teori, diantaranya Shariah Enterprise Theori (SET). Meutia dalam bukunya menyatakan, bahwa teori yang paling tepat untuk

${ }^{2}$ Hendrik Budi Untung, Corporate Social Responsibility, (Jakarta: Sinar Grafika Offet, 2009) hal. 1

${ }^{3}$ Fajar Nursahid, Tanggung Jawab Sosial BUMN, (Depok: Piramedia, 2006), hal. 27

${ }^{4}$ M.B. Hendrie Anto dan Dwi Retno Astuti, "Persepsi Stakeholder Terhadap Pelaksanaan Corporate Social Responsibility Kasus Pada Bank Syariah di DIY", Sinergi: Kajian Bisnis dan Manajemen, Vol. 10 No.1, Januari 2008. hal. 19

${ }^{5}$ Binhadi, "Pokok-pokok Pedoman GGBS dan Urgensi Kehadiran Pedoman GGBS", Presentasi pada Seminar Peluncuran Pedoman Umum Good Governance Bisnis Syariah, 3 November 2011. hal. 56 
mengungkapkan tanggung jawab sosial perusahaan, dalam hal ini perusahaan adalah yang memili nilai agama Islam, hal ini karena dalam Shariah Enterprise Theori, Allah adalah sumber amanah utama. Sedangkan sumber daya yang dimiliki oleh para stakeholders adalah amanah dari Allah yang di dalamnya melekat sebuah tanggung jawab untuk menggunakan dengan cara dan tujuan yang ditetapkan oleh sang Maha Pemberi Amanah. ${ }^{6}$ Dalam pandangan Islam kewajiban melaksanakan CSR bukan hanya menyangkut pemenuhan kewajiban secara hukum dan moral, tetapi juga strategi agar perusahaan dan masyarakat tetap survive dalam jangka panjang. Jika CSR tidak dilaksanakan maka akan terdapat lebih banyak biaya yang harus ditanggung perusahaan.

Menurut perspektif Islam kaum muslimin pada hakikatnya bersaudara dan saling tolong menolong, karena itu setiap perusahaan seharusnya tidak hanya mencari profit atau keuntungan saja tetapi hendaknya memperhatikan kondisi masyarakat sekitar serta membantu mereka agar dapat terlepas dari jerat kemiskinan. ${ }^{7}$ Pada sisi lain Rasulullah Muhammad SAW juga menggambarkan bahwa setiap manusia itu bersaudara bila satu atau sebagian anggota masyarakatnya miskin, maka yang lain turut perihatin dan merasa berkewajiban untuk mengentaskannya. ${ }^{8 S e b a g a i m a n a ~ h a d i t s ~ R a s u l u l l a h ~: ~}$

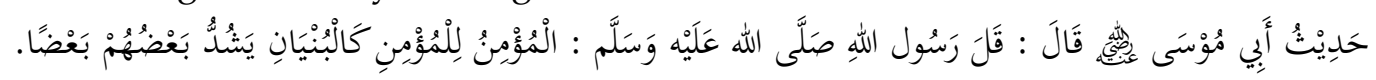
Artinya : Diriwayatkan dari Abu Musa ra. katanya : Rasulullah saw. bersabda: seorang mukmin terhadap mukmin yang lain adalah seperti sebuah bangunan dimana sebagiannya menguatkan sebagian yang lain.( HR. Shahih dan Bukhari $)^{9}$

Kegiatan berderma (filantropi) pada dasarnya telah menjadi tradisi dan kebiasaan masyarakat Indonesia terutama yang dilandasi oleh ajaran Agama, secara kultural pola yang mirip dapat ditentukan pada masyarakat di Asia pada umumnya. Dikawasan ini kegiatan berderma, baik secara material maupun amal harta dan benda maupun sumbangan tenaga sukarela, dipraktikkan secara luas di berbagai kegiatan sosial. ${ }^{10}$ Pemberian tersebut seharusnya tidak diberikan

\footnotetext{
${ }^{6}$ Inten Mutea, Menata Pengungkapan CSR di Bank Islam (Suatu Pendekatan Kritis), (Jakarta:Citra Pustaka Indonesia, 2010), hal. 45

${ }^{7}$ Zamir Iqbal. Pengantar Keuangan Islam (Teori \& Praktik). (Jakarta:Kencana, 2008), hal. 344

${ }^{8}$ Syahrin Harahap. Konsep Islam dan Implementasi Pemberdayaan (Yogyakarta: Tiara Wacana , 19990, hal. 100

${ }_{9}^{9}$ Al-Imam Abi Abdillah Muhammad bin Ismail bin Ibrahim Ibnu al-Mughirah, Shahih Bukhari (Bairut : ar- al-Fakru,1414H /1994 M), Juz 8 h. 102

${ }^{10 Z a i m ~ S a i d i ~ d k k . ~ M e m b a n g u n ~ K e m a n d i r i a n ~ B e r k a r y a, ~ P o t e n s i ~ d a n ~ P o l a ~ K e d e r m a w a n a n ~}$ serta Penggalangannya di Indonesia, (Jakarta: PIRAC, 2004), hal. 2
} 
secara cuma-cuma tetapi harus ada program berkesinambungan untuk memberdayakan masyarakat dilingkungan sekitar wilayah operasional agar masyarakat dapat ikut merasakan hal positif dari keberadaan perusahaan. Dalam implementasinya setiap perusahaan menderma dan kegiatan sosialnya melalui program CSR (Corporate Social Responsibility) atau Tanggung Jawab Sosial Perusahaan.

Citra perusahaan dimata masyarakat sangat berpengaruh terhadap produk yang dihasilkan oleh perusahaan tersebut, teknologi informasi sekarang ini memudahkan masyarakat dalam mengakses berbagai informasi dari penjuru dunia. Jika satu perusahaan tidak menunjukkan komitmen sosial yang baik disuatu daerah, informasi ini akan cepat tersebar luas ke berbagai penjuru dunia. Akibatnya akan terbentuk citra yang negatif sebaliknya, jika perusahaan menunjukkan komitmen sosial yang tinggi terhadap kegiatan kemanusiaan, pelestarian lingkungan, kesehatan masyarakat dan lain-lain maka akan terbentuk citra positif.

BUMN juga sudah menerapkan Coorporate Social Responsibility (CSR) melalui Undang-Undang Nomor 19 Tahun 2003 tentang BUMN melalui Program Kemitraan dan Bina Lingkungan (PKBL). ${ }^{11}$ Kinerja Coorporate Social Responsibility (CSR) yang baik tidak hanya mengakomodasi kebutuhan stakeholder, tetapi juga harus mengakomodasikan apa yang diberikan oleh stakeholder kepada perusahaan. Saat ini perusahaan-perusahaan memang telah banyak menerapkan program-program Coorporate Social Responsibility (CSR) untuk masyarakat. Tetapi kenyataan dalam pelaksanaannya tidak sedikit program-program yang tidak tepat sasaran dan tidak memberikan kontribusi yang signifikan untuk masyarakat.

PT. Perkebunan Nusantara IV (Persero) merupakan Badan Usaha Milik Negara (BUMN) yang bergerak pada bidang usaha agroindustri. PT. Perkebunan Nusantara IV (Persero) ini merupakan perusahaan yang cukup besar. Aktivitas industri yang dilakukan oleh perusahaan telah menghabiskan lahan hampir 175,244 hektar.

Sebagai bentuk tanggung jawabnya terhadap masyarakat, PTPN IV Sosa menyalurkan CSRnya kepada kelompok Rumah Tangga Miskin (RTM) dengan tujuan untuk meningkatkan kemandirian masyarakat serta memberikan bantuan langsung (BLM) untuk modal usaha agar mereka mendapatkan kehidupan yang

${ }^{11}$ Ibid, hal. 93-94 
6 | TAZKIR: Jurnal Penelitian Ilmu-ilmu Sosial dan Keislaman

Vol. 03 No. 1 Juni 2017

sejahtera. Dan salah satu desa yang mendapatkan dana bantuan melalui program PT. Perkebunan Nusantara IV adalah dikecamatan Sosa. Hal ini terlihat dari program bina lingkungan yang dilaksanakan BUMN masih bersifat secara lokal. Misalnya, pelaksanakan bantuan untuk usaha keci-kecilan dan koperasi (dalam bentuk pemberian kredit bunga rendah sebesar 5\%) diberikan kepada usaha kecil dan koperasi yang tidak memiliki kaitan bisnis perusahaan. Sejak tahun 20122015 PT. Perkebunan Nusantara IV telah memberikan bantuan sebagai berikut :

\section{Tabel 1}

\section{Realisasi Dana Program Kemitraan dan Bina Lingkungan PTPN IV Sosa}

\begin{tabular}{|c|c|c|c|c|}
\hline \multirow{2}{*}{$\begin{array}{c}\text { Sektor Bantuan Bina } \\
\text { Lingkungan }\end{array}$} & \multicolumn{4}{|c|}{ Tahun } \\
\hline & 2012 & 2013 & 2014 & 2015 \\
\hline Pendidikan/Pelatihan & 54.770 .000 & 31.875 .000 & 28.550 .000 & 48.300 .000 \\
\hline Korban bencana alam & - & - & 30.000 .000 & - \\
\hline Sarana Ibadah & 150.534 .450 & 379.241 .696 & 304.500 .000 & 41.750 .000 \\
\hline $\begin{array}{l}\text { Peningkatan } \\
\text { Kesehatan }\end{array}$ & 48.000 .000 & 9.493 .000 & 63.850 .000 & 60.683 .000 \\
\hline $\begin{array}{l}\text { Pengemb. } \\
\text { Prasarana/Sarana } \\
\text { Umum }\end{array}$ & 96.875 .000 & - & 234.350 .000 & 3.000 .000 \\
\hline $\begin{array}{l}\text { Sosial } \\
\text { Kemasyarakatan }\end{array}$ & 266.500 .000 & 33.000 .000 & 56.000 .000 & 45.000 .000 \\
\hline $\begin{array}{l}\text { Pelestarian Alam/ } \\
\text { Lingkungan }\end{array}$ & 399.000 .000 & 11.750 .000 & 180.000 .000 & 143.000 .000 \\
\hline TOTAL & 656.579 .450 & 465.359 .696 & 897.250 .000 & 341.733 .000 \\
\hline
\end{tabular}

\section{Sumber: PT.Perkebunan Nusantara IV-Sosa}

Berdasarkan data diatas, kita dapat melihat bahwa komitmen PT.PN IV Sosa dalam menjalankan program-program CSR secara berkelanjutan. Akan tetapi diduga belum sepenuhnya tanggung jawab sosial perusahaan itu terlaksanakan. Karena pada data dan dari hasil wawancara yang penulis lakukan belum ada perusahaan ini melaksanakan program-program yang bisa membangun jiwa masyarakat tersebut untuk membangun perekonomian yang lebih layak. ${ }^{12}$ Diantaranya Masyarakat masih banyak yang pengangguran, dan banyak usaha masyarakat disekitar perusahaan yang tidak berjalan, pendidikan

\footnotetext{
${ }^{12}$ Bapak Aswin Nasution, Wawancara tertutup di Komplek Plasmen Sosa Pada Pukul 11:00 Wib Tanggal 27 Desember 2016.
} 
yang masih rendah. Di samping itu program-program tersebut tidak dapat berjalan sesuai yang telah direncanakan. Masyarakat di sekitar perusahaan masih banyak mengeluhkan dan melakukan aksi protes terhadap perusahaan.

Sehingga berdasarkan uraian di atas, maka peneliti merumuskan ke dalam penelitian yang berjudul Analisis Implementasi Corporate Social Responsibility (CSR) dalam Pemberdayaan Masyarakat pada PT. Perkebunan Nusantara IV Sosa Ditinjau dari Perspektif Ekonomi Islam.

\section{Pemberdayaan Masyarakat}

Pemberdayaan masyarakat adalah proses pembangunan sumber daya manusia/masyarakat itu sendiri dalam bentuk penggalian kemampuan pribadi, kreatifitas, kompetensi dan daya pikir serta tindakan yang lebih baik dari waktu sebelumnya. Proses pemberdayaan mengandung dua kecenderungan. Pertama, proses pemberdayaan yang menekankan pada proses memberikan atau mengalihkan sebagian kekuatan, kekuasaan atau kemampuan kepada masyarakat agar individu lebih berdaya. Kecenderungan pertama tersebut dapat disebut sebagai kecenderungan primer dari makna pemberdayaan. Sedangkan kecenderungan kedua atau kecenderungan sekunder menekankan pada proses menstimulasi, mendorong atau memotivasi individu agar mempunyai kemampuan atau keberdayaan untuk menentukan apa yang menjadi pilihan hidupnya melalui proses dialog. ${ }^{13}$

\section{Corporate Social Responsibility (CSR)}

Corporate Social Responsibility (CSR) merupakan satu bentuk tindakan etis perusahaan/dunia bisnis yang diarahkan untuk meningkatkan ekonomi, yang dibarengi dengan peningkatan kualitas hidup bagi karyawan, masyarakat, dan alam sekitar perusahaan. fungsi CSR tidak hanya sebagai suatu kewajiban menjalankannya saja, namun berproses kepada dampak yang lebih dalam lagi yakni bagaimana CSR bisa menuntaskan kemiskinan dan berhasil menggerakan sektor riil. Namun dapat pula dikatakan bahwa apabila perusahaan telah menjalankan fungsi CSR ini ada baiknya pemerintah mengurangi pajak dimana CSR secara nyata telah membangun suatu daerah apalagi daerah tersebut merupakan daerah tempat perusahaan beroperasi. ${ }^{14}$

\footnotetext{
${ }^{13}$ Pranarka \& Vidhyandika, Strategi Pemberdayaan, (Bandung: Raja Grapindo, 2009), hal. 23

${ }^{14}$ Hendrik Budi Untung, Corporate Social Responsibility, ...hal. 1
} 
8 | TAZKIR: Jurnal Penelitian Ilmu-ilmu Sosial dan Keislaman

Vol. 03 No. 1 Juni 2017

Bisnis membutuhkan berbagai sumber daya alam untuk kelangsungan usaha, sehinga perusahaan bertanggung jawab untuk memeliharanya. Islam secara tidak langsung menganggap bisnis sebagai entitas yang kewajibannya terpisah dari pemiliknya, adanya CSR akan mengembangkan kemauan baik perusahaan tersebut. ${ }^{15}$ Sebagaimana hadits Rasulullah :

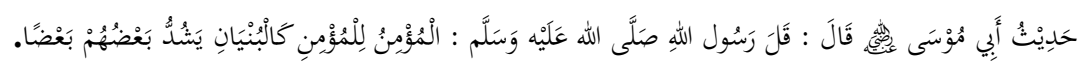

Artinya : Diriwayatkan dari Abu Musa ra. katanya: Rasulullah saw. bersabda: seorang mukmin terhadap mukmin yang lain adalah seperti sebuah bangunan dimana sebagiannya menguatkan sebagian yang lain.( HR. Shahih dan Bukhari ) ${ }^{16}$

Hadits diatas menjelaskan bahwa manusia pada hakekatnya makhluk sosial, saling membutuhkan untuk memenuhi keperluannya dan meningkatkan taraf hidupnya. Fitrah inilah yang ditegaskan oleh Islam. Islam memerintahkan untuk saling tolong menolong dalam kebaikan dan manfaat. Lebih lagi terhadap sesama umat muslim. Bahkan Islam mengibaratkan persaudaraan dan pertalian sesama muslim itu seperti satu bangunan, di mana struktur dan unsur bangunan itu saling membutuhkan dan melengkapi, sehingga menjadi sebuah bangunan yang kokoh, kuat dan bermanfaat lebih.

\section{Implementasi Corporate Social Responsibility}

Implementasi CSR tidak hanya sekedar upaya perusahaan untuk membayar utang sosial yang diakibatkan oleh proses bisnisnya, melainkan menjadi sebuah tanggung jawab sosial yang menjadi kewajiban bagi perusahaan untuk melaksanakannya. Bahkan lebih jauh dari itu, CSR seakan ditujukan untuk berlomba meningkatkan nilai dan citra perusahaan di mata pasar yang berujung pada komersialitas perusahaan.

Pelaksanaan CSR dalam Islam juga merupakan salah satu upaya mereduksi permasalahan-permasalahan sosial yang terjadi di masyarakat dengan mendorong produktivitas masyarakat dan menjaga keseimbangan distribusi kekayaan di masyarakat. Islam mewajibkan sirkulasi kekayaan terjadi

\footnotetext{
${ }^{15}$ Muhammad dan Lukman Fauroni, Visi Al-Quran tentang Etika dan Bisnis, (Jakarta: Salemba Diniyah, 2002). hal. 32

${ }^{16}$ al-Imam Abi Abdillah Muhammad bin Ismail bin Ibrahim Ibnu al-Mughirah, Shahih Bukhari (Bairut : Dar- al-Fakru,1414H /1994 M), Juz 8 h. 102
} 
pada semua anggota masyarakat dan mencegah terjadinya sirkulasi kekayaan hanya pada segelintir orang. ${ }^{17}$

Ajaran Islam memandang bahwa manusia sebagai wakil (khalifah) Tuhan di dunia tidak mungkin bersifat individualistik karena semua (kekayaan) yang ada di bumi adalah milik Allah semata, dan manusia adalah kepercayaannya dibumi. Sehingga salah satu wujud penerapannya misalnya larangan riba, maka pemilik modal selalu terlibat langsung dan bertanggungjawab terhadap jalannya perusahaan miliknya, bahkan terhadap buruh yang dipekerjakannya. ${ }^{18}$

Perusahaan dalam sistem Ekonomi Islam adalah perusahaan keluarga, bukan Perseron Terbatas yang pemegang sahamnya dapat menyerahkan pengolaan perusahaan begitu saja pada orang yang ditunjuk sebagai direktur atau manager yang digaji. Sehubungan dengan sistem ini, maka tidak ada perusahaan yang menjadi sangat besar, seperti di dunia kapitalis barat, tetapi juga tidak ada perusahaan yang tiba-tiba bangkrut atau dibangkrutkan.

\section{Shariah Enterprise Theory (SET)}

Etika berbisnis dalam ekonomi Islam termuat dalam lebih seperlima ayatayat dimuat dalam Al-qur'an. Etika yang bersumber dari ajaran agama mengandung prinsip yang berkaitan dengan nilai-nilai kebenaran yang berkaitan sikap dan perilaku yang dikasih Tuhan. Hans Kung menyebutkan pada intinya ada persamaan prinsip-prinsip nilai-nilai dasar etika yang ada dalam ketiga agama Nabi Ibrahim ini yaitu :19

a. Keadilan : kejujuran, mempergunakan kekuatan untuk menjaga kebenaran.

b. Saling menghormati: cinta dan perhatian terhadap orang lain.

c. Pelayanan: manusia hanya pelayan, pengawas sumber-sumber alam.

d. Kejujuran: kejujuran dan sikap dapat dipercaya dalam semua hubungan manusia, dan integritas yang kuat.

Menurut Meutia terdapat beberapa prinsip yang sebetulnya menggambarkan adanya hubungan antara manusia dan penciptanya, yaitu Allah SWT. Prinsip-prinsip ini adalah berbagi dengan adil, Rahmatan lil'alamīn (Rahmat

\footnotetext{
${ }^{17}$ Yusanto dan Yunus, Etika Bisnis dalam Islam, Jakarta: Putra medika, 2009), hal. 165 ${ }^{18}$ Ibid, hal. 217

${ }^{19}$ Dikutip dari Sebuah Artikel di Republika Online: Nonem : Manajemen Bernilai Islam, Republika Online, 08 Mei 2002. Vol. 12. hal. 3
} 
10 | TAZKIR: Jurnal Penelitian Ilmu-ilmu Sosial dan Keislaman

Vol. 03 No. 1 Juni 2017

bagi seluruh alam, dan mașlahah (kepentingan masyarakat). ${ }^{20}$ Menurut AlGhazali, prinsip-prinsip ini sebetulnya punya keterkaitan yang kuat dengan tujuan ekonomi syariah yang mengedepankan kepentingan masyarakat banyak. ${ }^{21}$

\section{METODE PENELITIAN}

Penelitian ini dilakukan pada PT. Perkebunan Nusantara IV Kecamatan Sosa Kabupaten Padang Lawas Provinsi Sumatera Utara. Jenis lapangan (field research) dengan penelitian kualitatif. Informan dalam penelitian ini adalah Pimpinan dan karyawan perusahaan Bagian Kemitraan dan Bina Lingkungan sebanyak 6 orang serta masyarakat yang mendapat Bantuan Program Kemitraan dan Bina Lingkungan PT. Perkebunan Nusantara IV Sosa sebanyak 20 kelompok yang aktif. Sumber data penelitian ini adalah data sekunder dan data primer.

\section{HASIL PENELITIAN}

1. Program Corporate Social Responsibility (CSR) PT. Perkebunan Nusantara IV Sosa dalam Pemberdayaan Masyarakat.

Ada tiga prinsip yang mendasari CSR (Corporate Social Responsibility) PTPN IV yakni profit, people dan planet yang juga dikenal dengan istilah Triple Bottom Lines, yang telah diimplementasikan oleh PTPN IV sejak lama pada Tahun 198710 kabupaten yang merupakan area bisnis PT. Perkebuann Nusantara IV. ${ }^{22}$ Landasan hukum yang mendasari pelaksanaan CSR pada PTPN IV adalah undang-undang no 19 tahun 2003, keputusan menteri BUMN dan keputusan direksi PTPN IV. Bentuk program CSR yang telah dilaksanakan oleh PTPN IV adalah meliputi:23

\section{a. Program Kemitraan}

Program kemitraan adalah program untuk meningkatkan kemampuan usaha kecil agar menjadi tangguh dan mandiri melalui pemanfaatan dana dari bagian laba BUMN. Program ini merupakan kerja sama usaha antara usaha kecil dan menengah atau dengan besar

\footnotetext{
${ }^{20}$ Inten, Meutia .Menata Pengungkapan CSR di Bank Islam (Suatu Pendekatan Kritis), (Jakarta:Citra Pustaka Indonesia, 2010), hal. 187

${ }^{21} \mathrm{M}$ Umer Chapra. The Islamic Vision of Development in The Light of Maqasid al-Shari'ah. Jeddah: Islamic Research and Training Institute Islamic Depelopment Bank. 2007. hal. 6

${ }^{22}$ Nasrul, Manajer PTPN IV-Sosa, Wawancara di Kantor Kebun Plasma Sosa, Selasa Jam 11:00 Wib tanggal 27 Desember 2016.

${ }^{23}$ Bapak Parmohonan Harahap, Kepala Bagian PKBL PTPN IV-Sosa, Wawancara di Kantor Kebun Plasma Sosa, Selasa Jam 14.00 Wib tanggal 27 Desember 2016.
} 
disertai dengan binaan dan pembangunan oleh usaha menengah atau usaha besar dengan prinsip saling memerlukan, saling memperkuat, dan saling menguntungkan program ini meliputi:

1) Memberikan pinjaman untuk membiayai modal kerja dan atau pembelian aktiva tetap dalam rangka meningkatkan produksi dan penjualan.

2) Memberikan pinjaman khusus yang digunakan untuk membiayai kebutuhan dana pelaksanaan kegiatan usaha Mitra Binaan (MB) yang bersifat pinaman tambahan dan jangka pendek dalam rangka memenuhi pesanan dari rekan usaha Mitra Binaan.

3) Memberikan dana pembinaan kemitraan yang digunakan untuk membiayai pendidikan, pelatihan, pemagangan, pemasaran, promosi dan hal-hal yang menyangkut peningkatan produktivitas Mitra Binan serta untuk penelitian berkaitan dengan Program Kemitraan.

Program kemitraan yang dilakukan oleh PTPN IV Sosa, adalah :

1) Pembiayaan modal kerja dan investasi. Penggunaan dana pinjaman dapat dibagi beberapa sektor antara lain : Sektor Industri, Sektor Perdagangan, Sektor Pertanian, Sektor Peternakan, Sektor Perkebunan, Sektor Perikanan, Sektor Jasa dan Sektor lainnya.

2) Pinjaman Khusus (Jangka Pendek)

3) Hibah, seperti : Pendidikan, Pelatihan, Pemagangan, Pemasaran, Promosi, Pameran, dan lain-lain.

\section{b. Program Bina Lingkungan}

Program Bina Lingkungan adalah program pemberdayaan kondisi sosail masyarakat oleh BUMN melalui pemanfaatan dana dari bagian laba BUMN (Community Development). Program bina lingkungan yang dilakukan oleh PT. PN-IV Sosa, meliputi : Memberikan bantuan untuk korban bencana alam, untuk pendidikan dan pelatihan peningkatan kesehatan, pengembangan prasarana dan atau sasaran umum, sarana ibadah, serta pelestarian alam.

Pembangunan ekonomi kerakyatan yang dilakukan PTPN IV Sosa disekitar wilayah kebun adalah meliputi $:^{24}$

${ }^{24}$ Bapak Arsan Siregar, Kepala Bagian HUMAS PTPN-IV Sosa, Dokumen beserta Wawancara pada Hari Selasa Pukul 11.00 Wib tanggal 17 Januari 2017 
12 | TAZKIR: Jurnal Penelitian Ilmu-ilmu Sosial dan Keislaman

Vol. 03 No. 1 Juni 2017

1) Pembangunan Kebun Plasma dengan pola Profit Sharing di Kabupaten Padang Lawas

2) Berperan dalam kegiatan Program Ketahanan Pangan melalui Program Penananam Jagung di lahan lahan tidak produktif/kritis, dengan mengikut sertakan kelompok-kelompok tani di sekitar kebun.

Program kemitraan yang dilakukan adalah melalui pemberian dana kemitraan untuk usaha kecil dan menengah yang bergerak di sektor industri kecil, perdagangan, pertanian, perkebunan, peternakan, perikanan, jasa dan lainnya. Pada tahun 2015, total dana kemitraan yang telah disalurkan adalah senilai Rp 385 Juta. Sedangkan program bina lingkungan adalah meliputi penyaluran dana kepada masyarakat berupa bantuan bencana alam, pendidikan dan pelatihan, peningkatan kesehatan masyarakat, pengembangan prasarana umum, pembangunan sarana ibadah dan pelestarian alam/lingkungan. Realisasi penyaluran dana bina lingkungan sepanjang tahun 2014 mencapai Rp. 1,2 Miliar. Selain dana yang bersumber dari penyisihan Laba Bersih, PTPN IV juga menganggarkan dana CSR sebagai biaya yang dibebankan kepada perusahaan. Sepanjang tahun 2015, perusahaan telah menyalurkan dana CSR sebesar Rp. 1,90 miliar dari total dana yang dianggarkan sebesar 4 miliar. $^{25}$

Keseluruhan dana CSR tersebut disalurkan untuk peningkatan sarana dan prasarana masyarakat umum sekitar unit usaha, antara lain sebagai berikut $:^{26}$

a. Pengerasan jalan (telfot) sepanjang $1.123 \mathrm{~m}$ di Desa Huta raja tinggi Kec. Huta Raja Tinggi Kab. Padang Lawas

b. Pembuatan parit permanen sepanjang $400 \mathrm{~m}$ di Kecamatan Sosa Kabupaten Padang Lawas

c. Pembangunan 1 unit jembatan ukuran 6x4x5 m di Desa Mananti Kecamatan Huta Raja Tinggi Kabupaten Padang Lawas.

\footnotetext{
${ }^{25} \mathrm{Ibu}$ Sulastri, Bendahara PT. Perkebunan Nusantara IV-Sosa, Wawancara tertutup di Kantor PTPN-IV Sosa pada Hari Selasa Pukul 09.00 Wib Tanggal 17 Januari 2017.

${ }^{26}$ Bapak Arsan Siregar, Kepala Bagian HUMAS PTPN-IV Sosa, Dokumen PTPN IV beserta Wawancara pada Hari Selasa Pukul 11.00 Wib tanggal 17 Januari 2017
} 
d. Pembauatan parit permanen sepanjang $1.200 \mathrm{~m}$ dan pembuatan 3 unit plat beton di Desa Huta Raja Lama kecamatan Sosa Kabupaten Padang Lawas.

e. Peningkatan/pengerasan jalan dengan batu petrun sepanjang $3.300 \mathrm{~m}$ di Plasma Sosa Kab. Padang Lawas.

f. Peningkatan/pengerasan jalan dengan batu koral sepanjang $1.500 \mathrm{~m}$ di Trans Sosa Tanjung Ale Kab. Padang Lawas.

\section{Penerapan Corporate Social Responsibility (CSR) terhadap Triple Bottom}

\section{Line}

Konsep Triple Bottom Line (TBL) yang secara luas diperkenalkan oleh Jhon Eklington, terkait dengan operasi perusahaan memperhatikan bukan hanya aspek ekonomis maupun keuntungan (Profit) semata, namun harus memperhatikan keadaan masyarakat (People) dan keadaan lingkungan (Planet) sekitar. Ketiga faktor ini saling berkaitan antara dengan yang lainnya dan bersifat dinamis dan tergantung pada kondisi dan tekanan sosial, politik, konomi dan lingkungan, serta adanya kemungkinan konflik kepentingan. TBL digunakan sebagai kerangka dalam mengukur dan malaporkan kinerja perusahaan mencakup parameter-parameter sekonomi, sosial dan lingkungan dengan memperhatikan kebutuhan stakeholder (konsumen, pekerja, mitra bisnis, pemerintah, masyarakat lokal dan masyarakat luas) dan shareholder untuk meminimalkan adanya gangguan atau kerusakan pada manusia dan lingkungan dari berbagai aktivitas perusahaan.

TBL pada implementasi CSR di PTPN-IV SOSA bukan hanya merupakan sekedar laporan kinerja tetapi juga sebagai suatu pendekatan untuk memperbaiki pengambilan keputusan tentang kebijakan dan program ke arah yang lebih baik dengan mempertimbangkan aspek ekonomi, limgkungan dan masyarakat sekaligus. Implementasi CSR pada konsep TBL seringkali menjadi bias ketika kelihatannya perusahaan hanya melakukan kegiatan bantuan sebagai pemadam konflik sementara kepada masyarakat dan mangklaim bantuan telah malakukan CSR. Hal ini sanga bertolak belakang dengan konsep yang tidak hanya sebagai program bantuan untuk menghindari tekanan dari pihak lain, misalnya tekanan masyarakat ataupun merupakan alat dalam pembentukan citra baik dari 
14 | TAZKIR: Jurnal Penelitian Ilmu-ilmu Sosial dan Keislaman

Vol. 03 No. 1 Juni 2017

perusahaan melainkan merupakan kegiatan pemberdayaan yang berkesinambungan ke arah yang lebih baik.

Berdasarkan rencana strategis CSR PTPN IV Sosa, program yang menjadi prioritas adalah konsep program Lima Pilar Pengembangan Masyarakat yang dikoordinir oleh Comdev section dan Proyek Pembangunan Berkelanjutan atau Sustainable Development Project yang dikoordinir oleh SDP section. Program Lima Pilar yang di lakukan secara tersusun dan berkelanjutan di kecamatan Sosa Binaan PTPN IV Sosa diantaranya: ${ }^{27}$

\section{a. Pilar Pendidikan}

Program pendidikan yang dilakukan bertujuan untuk meningkatkan indeks pembangunan manusia di desa-desa binaan sekitar wilayah operasi perusahaan. Program-program tersebut meliputi pembangunan dan renovasi gedung-gedung sekolah (PAUD, SD, SMP,dan SMA), beasiswa, latihan-latihan keterampilan melalui Sekolah Magang PTPN IV Sosa, perpustakaan, dan fasilitas serta perlengkapan lainnya berupa buku-buku, bangku, dan meja.

\section{b. Pilar Ekonomi}

Salah satu program yang dilakukan PTPN IV Sosa di bidang ekonomi adalah dengan membangun usaha kecil dan menengah, yang disesuaikan dengan potensi yang ada Kecaman Sosa binaan. Usahausaha pemberdayaan yang dilakukan mencakup serangkaian pelatihan, bimbingan dan arahan tentang bagaimana mengembangkan bisnis mereka itu serta bantuan modal usaha, program ini juga bekerjasama dengan PKBL. Perusahaan membangun berbagai infrastruktur, seperti jalan, jembatan, rumah ibadah di Kecamatan Sosa binaan sekitar pabrik perusahaan beroperasi. Berkat pemberdayaan itu, banyak diantara mereka telah menjadi panutan dibidangnya masing-masing, seperti peternakan ayam, konveksi, pembuatan kue, dan bengkel sepeda motor.

c. Pilar Kesehatan.

Program ini bertujuan memberikan prasarana untuk meningkatkan kesehatan masyarakat desa setempat, dan secara umum juga merupakan partisipasi PTPN IV Sosa dalam program pemerintah

${ }^{27}$ Bapak Sahrul Siagian, Karyawan PTPN IV Sosa, Wawancara pada hari Kamis pukul 11:30 tanggal 2 Januari 2017 
membangun masyarakat sekitar yang sehat serta membantu prasarana pendukung Posyandu di Kecamatan Sosa, Komplek Plasma Sosa. Selain itu PTPN IV Sosa juga mengadakan Posling (Puskesmas Keliling) di setiap desa binaannya dengan menggunakan sistem rolling bergantian di setiap desanya. Program ini memberikan bantuan PMT, pengurangan jumlah balita gizi buruk, penyuluhan kesehatan dan pengobatan gratis bagi masyarakat yang berada di Kecamatan Sosa binaan CSR unit Kebun Sosa.

\section{d. Pilar Sosbudag (Sosial, Budaya, dan Agama) dan Olahraga}

Pada bidang ini PTPN IV Sosa membangun berbagai infrastruktur, seperti jalan, jembatan, rumah ibadah di desa-desa binaan sekitar daerah operasial perusahaan. PTPN IV Sosa juga memberikan pembinaan kepada generasi muda melalui pemberian sarana untuk kegiatan olah raga, memelihara budaya lokal, seperti tarian Degung, Reog dan kesenian lokal lainnya. CSR PTPN IV Sosa juga mengadakan program pembinaan sepak bola dengan peserta dari Kecamatan Sosa desa binaan. Pada bulan Ramadhan PTPN IV juga mengadakan buka puasa bersama yang diadakan di Masjid yang berada di lingkungan pabrik dengan mengundang perwakilan tokoh masyarakat Di Kecamatan Sosa binaannya. Selain itu, pada Hari Raya Idul Fitri perusahaan juga melakukan pembagian zakat kepada masyarakat sekitar dan membantu para korban Sinabung, dan Korban kebanjiran di Kabupaten Padang Lawas berupa paket bantuan yang merupakan sumbangan pribadi dari Manager PTPN IV Sosa.

\section{e. Pilar Keamanan}

Salah satu kegiatan yang dilakukan melalui bidang keamanan ini dengan menggalang kerja sama dengan masyarakat guna memelihara suasana aman melalui pembinaan Pam Swakarsa. Hal itu dilaksanakan dengan memberikan pelatihan-pelatihan keamanan kepada masyarakat atau petugas Linmas di desa-desa binaan serta menyediakan fasilitasfasilitas pendukung dan peralatan, seperti pos keamanan lingkungan dan seragam petugas keamanan lokal.

Berdasarkan penjelasan mengenai pandangan, dan pelaksanaan CSR PTPN-IV Sosa maka dapat terlihat keterkaitan antara kebijakan dan pendangan perusahaan dalam pelaksanaan CSR yang berlandaskan 
16 | TAZKIR: Jurnal Penelitian Ilmu-ilmu Sosial dan Keislaman

Vol. 03 No. 1 Juni 2017

konsep triple bottom lines dan kerangka Lima Pilar Pembangunan PTPN IV Sosa. Kegiatan CSR yang dilakukan perusahaan memiliki tujuan umum untuk membangun kemandirian masyarakat dan peningkatan perekonomian dengan mengembangkan masyarakat di Kecamatan Sosa Binaan.

Selain itu, besarnya dana CSR dari penyisihan laba bersih PTPN IV Sosa yakni sebesar 3-5 \% dianggap tidak sebanding dengan luas area lahan perkebunan dan laba bersih yang didapatkan oleh PTPN IV Sosa, misalnya pada tahun 2015 dana yang disalurkan untuk CSR dari penyisihan laba bersih adalah senilai 22,57 atau senilai 2,8 \% dari laba bersih yang didapatkan perusahaan. Sedangkan pada tahun 2016 ini, PTPN IV Sosa telah menganggarkan dana CSR senilai 10 miliar atau sebesar 5\% dari laba bersih perusahaan pada tahun 2014. Meski terdapat peningkatan dana CSR yang dianggarkan ternyata masyarakat tetap menganggap dana tersebut kurang dan tidak sebanding dengan luas area perkebunan PTPN IV Sosa. ${ }^{28}$

Hal ini seperti yang diungkapkan oleh Ketua komisi C DPRD Sumatera Utara dalam sebuah pertal berita online, Marasal hutasohit, yang mengatakan bahwa dana CSR yang di gelontorkan ke masyarakat sangat minim sekitar 3-5\%, dan tidak sebanding dengan luasan areal PTPN IV Sosa yang wilayahnya mencakup sejumlah beberapa kecamatan. Dalam hal pembinaan lingkungan, PTPN IV Sosa masih banyak berfokus pada perbaikan infrastruktur di lingkungan sekitar yakni perbaikan jalan dan pembangunan saluran irigasi. Sementara itu untuk perbaikan ekosistem yang rusak akibat adanya area perkebunan sawit seluas 175.244 Ha masih belum banyak disentuh. Saat ini PTPN IV Sosa hanya memiliki hutan cadangan seluas 5.649 atau sebesar 3\% dari luas lahan yang dimiliki oleh PTPN IV Sosa. Luas lahan untuk hutan cadangan yang hanya sebesar $3 \%$ ini tentunya terlalu kecil jika dibandingkan dengan luas area perkebunan kelapa sawit, bahkan luas lahan hutan cadangan ini tidak sebesar luas area perumahan dan pabrik PTPN IV Sosa. Padahal dapat diketahui bahwa pembangunan perkebunan sawit telah merusak ekosistem yang dapat mengakibatkan

${ }^{28}$ Bapak Saripun Harahap, Karyawan PTPN IV Sosa, Wawancara tertutup Pada Pukul 13:30 Wib di kediaman Beliau di Komplek Plasmen Tanggal 04 Januari 2017 
flora dan fauna kehilangan habitatnya, mengurangi ketersediaan air dan sedimentasi serta munculnya resiko bencana tanah longsor yang lebih besar. $^{29}$

Menghadapi permasalahan ini, PTPN IV Sosa belum banyak memberikan solusi yang cukup berarti, PTPN IV Sosa hanya terlibat pada kegiatan-kegiatan penanaman hutan yang bersifat eventual dengan menyumbangkan beberapa bibit tanamannya. Padahal dengan lahan perkebunan yang sangat luas, CSR PTPN IV Sosa harusnya lebih banyak berfokus untuk perbaikan dan pelestarian alam dibandingkan dengan bentuk CSR yang lain.

Secara singkat dapat dikatakan evaluasi CSR untuk PTPN IV adalah sebagai berikut:

1) Penyaluran dana CSR lebih dimaksimalkan dan disesuaikan dengan dana yang dianggarkan. Karena adanya indikasi penyaluran dana CSR tidak sebesar dana yang dianggarkan sehingga masyarakat akan tetap merasa dana CSR belum cukup.

2) Kurangnya pengawasan penyaluran dana CSR sehingga CSR tidak diterima secara merata oleh masyarakat.

3) Program CSR yang ada tidak berdasarkan pada aspek sustainability development, sehingga masyarakat tidak mendapatkan kemanfaatan dari program CSR ini.

4) Minimnya program CSR yang mencakup perbaikan lingkungan yang terjadi karena kerusakan ekosistem akibat adanya area perkebunan dan industri kelapa sawit.

Selain CSR yang dilakukan PTPN IV Sosa yang diimplementasikan dalam bentuk PKBL, perusahaan ini juga ikut serta dalam beberapa program yang memperhatinkan masyarakat dan lingkungan sekitarnya yang dilakukan oleh pemerintah daerah. Beberapa program yang dilakukan seperti : ${ }^{30}$

a. Program langit biru mendukung program pemerintah tentang langit biru dengan mengurangi berkurangnya ozon yang semakin lama semakin berkurang karena dampak polusi dan dananya dimasukkan ke dalam biaya perusahaan.

${ }^{29}$ Bapak Salman Siregar, Warga Desa Aektinga Kecamatan Sosa, Wawancara pada Pukul 15:30 Wib tanggal 07 Januari 2017

${ }^{30}$ Dokumen PTPN IV Sosa, Bagian PKBL Tahun 2012-2015. 
18 | TAZKIR: Jurnal Penelitian Ilmu-ilmu Sosial dan Keislaman

Vol. 03 No. 1 Juni 2017

b. Pelestarian lingkungan yang diadakan warga dikecamatan Sosa melalui program Go Green untuk mendukung lingkungan yang nyaman, kondusif melalui program pemeliharaan lingkungan. Go Green telah menanam sekitar 543 pohon dan direncanakan untuk lahan seluas 12.000 hektar akan membutuhkan 20.000 .000 pohon.

3. Tinjauan Shariah Enterprise Theory (SET) terhadap Program Corporate Social Responsibility (CSR) pada PT. Perkebunan Nusantara IV Sosa

Program Kemitraan dan Bina Lingkungan (PKBL) selaras dengan pandangan Islam tentang manusia sehubungan dengan dirinya sendiri dan lingkungan sosial, dapat dipresentasikan dengan empat aksioma yaitu kesatuan (tauhid), keseimbangan (Equilibrum), kehendak bebas (Free will) dan tanggung jawab (Responsibility). Islam sangat mendukung Corporate Social Responsibility (CSR) karena tidak dapat dipungkiri bahwa bisnis menciptakan banyak permasalahan sosial, dan perusahaan bertanggung jawab menyelesaikannya. Bisnis membutuhkan berbagai sumber daya alam untuk kelangsungan usaha, sehinga perusahaan bertanggung jawab untuk memeliharanya. Islam secara tidak langsung menganggap bisnis sebagai entitas yang kewajibannya terpisah dari pemiliknya, adanya CSR melalui program kemitraan dan bina lingkungan akan mengembangkan kemauan baik perusahaan tersebut. ${ }^{31}$

Unsur Shariah Enterprise Theory (SET) ada 3 bagian sebagaimana yang dijelaskan Meutia dalam bukunya :

a. Prinsip berbagi dengan adil

Dimana dikatakan dalam konteks berbagi Adil disini adalah Masyarakat ikut merasakan adanya keadilan di dalam penyaluran program yang dilakukan oleh PTPN IV Sosa di dalam melaksanakan tanggung jawab sosial perusahaan. Menurut Sahidin, keadilan dalam kegiatan ekonomi ditetapkan dalam kaidah fiqih, bertujuan untuk mewujudkan kesejahteraan umat. $^{32}$ Prinsip keadilan Islam sangat kentara dalam praktik mudharabah (berbagi keuntungan dan kerugian), dimana pemilik modal dan pengguna modal (pekerja) ditempatkan pada posisi yang sejajar. Prinsip adil dalam Islam adalah

${ }^{31}$ Selvian, Etika Bisnis Islam Dalam Perusahaan. (Jakarta:Rajawali Pers), 2011, h. 6-9

${ }^{32}$ Ahmad Sahidin. Membaca Naskah Sejarah Pemikiran Ekonomi Islam, (Online), (http://albanduni.wordpress.com diakses 16 Nopember 2016), hal. 34 
tidak mendzalimi dan tidak didzalimi. Implikasinya dalam aktivitas ekonomi ialah bahwa pelaku ekonomi tidak dibenarkan mengejar keuntungan pribadi, seandainya hal tersebut merusak atau merugikan pihak lain.

PTPN IV Sosa memberikan bantuan mitra kepada Masyarakat sekitar perusahaan ditinjau dari prinsip berbagi Adil bahwa dapat dikatan perusahaan Adil dalam melaksanakan tanggungjawabnya kepada masyarakat.

Jika ditinjau menurut SET bahwa program PTPN IV Sosa dilihat dari Prinsip berbagi adil mengajarkan bahwa dalam setiap harta ada bagian atau hak untuk makhluk Allah yang lain. Selain itu, berbagi juga dimaknai sebagai berbagi hal yang non-materiil, seperti berbagi kebaikan serta menjalankan amar ma'ruf nahi munkar (saling menasehati atau menganjurkan berbuat kebaikan dan mencegah kejahatan).

Tabel 2

Tanggapan responden tentang Prinsip berbagi dengan Adil

\begin{tabular}{|c|c|c|c|c|c|c|c|}
\hline \multirow{2}{*}{ No } & \multirow{2}{*}{ Program PKBL } & \multicolumn{5}{|c|}{ Tanggapan Responden } & \multirow{2}{*}{ Jumlah } \\
\cline { 3 - 7 } & & SS & S & N & TS & STS & \\
\hline 1 & Mitra Binaan & 11 & 6 & 1 & 1 & 2 & 20 \\
\hline 2 & Beasiswa & 13 & 5 & 2 & 0 & 0 & 20 \\
\hline 3 & Kesehatan & 15 & 4 & 1 & 0 & 0 & 20 \\
\hline 4 & Bencana Alam & 18 & 2 & 0 & 0 & 0 & 20 \\
\hline 5 & Penghijauan & 17 & 3 & 0 & 0 & 0 & 20 \\
\hline 6 & Dana Hibah & 16 & 3 & 1 & 0 & 0 & 20 \\
\hline & Jumlah & $\mathbf{9 0}$ & $\mathbf{2 3}$ & $\mathbf{5}$ & $\mathbf{1}$ & $\mathbf{2}$ & \\
\hline & Presentase & $\mathbf{9 0} \%$ & $\mathbf{8} \%$ & $\mathbf{1 \%}$ & - & $\mathbf{1 \%}$ & $\mathbf{1 0 0} \%$ \\
\hline
\end{tabular}

Olahan Wawancara Responden

Analisis tabel diatas menunjukkan bahwa dilihat dari sudut pandang program CSR yang di implementasikan terhadap masyarakat dalam pemberdayaan sudah dapat dikatakan berbagi dengan Adil, indikator dikatakan Adil antara lain: Semua masyarakat dapat meminjam, Transparan/Kejujuran, tidak merasa didzalimi dan sesuai kebutuhan masyarakat walaupun ada beberapa responden yang menyatakan tidak tercapainya keadilan di dalam penerapan program CSR. Namun, secara keseluruhan perusahaan ini sudah tergolong Adil dalam menerapkan 
20 | TAZKIR: Jurnal Penelitian Ilmu-ilmu Sosial dan Keislaman

Vol. 03 No. 1 Juni 2017

programnya terhadap masyarakat sekitar perusahaan karena dilihat pada responden yang menyatakan sangat setuju sebanyak $90 \%$ dan Setuju sebanyak $8 \%$.

\section{b. Prinsip Rahmatan Lil'alamīn}

Prinsip Rahmatan Lil'alamin bermakna keberadaan manusia seharusnya bisa menjadi manfaat bagi makhluk Allah lainnya. Dalam kerangka perusahaan, mka manfaat keberadaan perusahaan seharusnya dapat dirasakan oleh semua pihak baik yang terlibat maupun tidak terlibat langsung dalam aktivitas perusahaan. Menurut Meutia bentuk rahmat atau keberpihakan ini dapat berupa pemberian zakat, infak, dan sedekah maupun pemberian pembiayaan kepada para pengusaha kecil..$^{33}$

Dalam prinsip Rahmatan Lil'alamīn, PTPN IV Sosa pengimplementasinnya dalam programnya sudah cukup bermanfaat bagi masyarakat sekitar diantaranya: Bantuan kemitraan, pelestarian alam, pemberian beasiswa, bantuan kesehatan beserta bantuan bencana alam. Berdasarkan hasil wawancara terhadap masyarakat, Secara umum tanggung jawab sosial.

Tabel 3

Tanggapan Responden tentang Prinsip Raḥmatan Lil'alamīn

\begin{tabular}{|c|c|c|c|c|c|c|c|}
\hline \multirow{3}{*}{ No } & \multirow{3}{*}{ Program PKBL } & \multirow{2}{*}{\multicolumn{5}{|c|}{$\begin{array}{c}\text { Tanggapan Responden } \\
\text { Prinsip Rạ̣matan Lil'alamīn }\end{array}$}} & \multirow{3}{*}{ Jumlah } \\
\hline & & & & & & & \\
\hline & & SS & $\mathrm{S}$ & $\mathbf{N}$ & TS & STS & \\
\hline 1 & Mitra Binaan & 12 & 5 & 3 & 0 & 0 & 20 \\
\hline 2 & Beasiswa & 15 & 2 & 3 & 0 & 0 & 20 \\
\hline 3 & Kesehatan & 16 & 3 & 1 & 0 & 0 & 20 \\
\hline 4 & Bencana Alam & 18 & 2 & 0 & 0 & 0 & 20 \\
\hline 5 & Penghijauan & 18 & 2 & 0 & 0 & 0 & 20 \\
\hline 6 & Dana Hibah & 16 & 4 & 1 & 0 & 0 & 20 \\
\hline & Jumlah & 115 & 18 & 8 & 0 & 0 & \\
\hline & Presentase & $92 \%$ & $7 \%$ & $1 \%$ & - & - & $100 \%$ \\
\hline
\end{tabular}

Analisis tabel diatas menunjukkan bahwa dilihat dari sudut pandang program CSR yang di implementasikan terhadap masyarakat

${ }^{33}$ Inten, Meutia, ...hal 221 
dalam pemberdayaan sudah dapat dikatakan Rahmatan Lil'alamin/merasakan manfaat adanya program perusahaan menerapkan programnya, keadaan sekarang dalam penerapan program CSR oleh perusahaan terhadap masyarakat sudah dirasakan manfaat. Secara keseluruhan perusahaan ini sudah tergolong dapat memberi manfaat dalam menerapkan programnya terhadap masyarakat sekitar perusahaan karena dilihat pada responden yang menyatakan sangat setuju sebanyak $92 \%$ dan Setuju sebanyak $7 \%$.

\section{Prinsip Maṣlahah (Kepentingan Masyarakat)}

Berikut ini gambaran dari tanggapan responden tentang program CSR dihubungkan dengan prinsip Maṣlaḥah. Berikut ini gambaran dari tanggapan responden terhadap implementasi CSR dari tinjauan adan tidaknya prinsip Maṣlaḥah yang muncul pada penerapannya tersebut.

\section{Tabel 4}

Tanggapan Responden tentang CSR dengan Prinsip Maṣlaḥah

\begin{tabular}{|c|c|c|c|c|c|c|c|}
\hline \multirow{3}{*}{ No } & \multirow{3}{*}{ Program PKBL } & \multicolumn{5}{|c|}{ Tanggapan Responden } & \multirow{3}{*}{ Jumlah } \\
\hline & & \multicolumn{5}{|c|}{ Prinsip Mașlahah } & \\
\hline & & SS & $S$ & $\mathbf{N}$ & TS & STS & \\
\hline 1 & Mitra Binaan & 16 & 2 & 2 & 1 & 1 & 20 \\
\hline 2 & Beasiswa & 16 & 3 & 1 & 0 & 0 & 20 \\
\hline 3 & Kesehatan & 18 & 1 & 1 & 0 & 0 & 20 \\
\hline 4 & Bencana Alam & 18 & 2 & 0 & 0 & 0 & 20 \\
\hline 5 & Penghijauan & 17 & 2 & 1 & 0 & 0 & 20 \\
\hline 6 & Dana Hibah & 15 & 3 & 2 & 0 & 0 & 20 \\
\hline \multicolumn{2}{|r|}{ Jumlah } & 110 & 23 & 7 & 1 & 1 & \\
\hline \multicolumn{2}{|r|}{ Presentase } & $91 \%$ & $8 \%$ & $1 \%$ & - & - & $100 \%$ \\
\hline
\end{tabular}

Analisis tabel diatas menunjukkan bahwa perusahaan sudah dapat memberikan Mașlahah/manfaat terhadap masyarakat dalam menjalankan program CSR nya. Secara garis besar perusahaan dapat dikategorikan baik terhadap program yang disalurkan terhadap masyarakat sekitar perusahaan. Karena dilihat dilihat pada responden yang menyatakan sangat setuju sebanyak $90 \%$ dan Setuju sebanyak $8 \%$.

Program kemitraan merupakan realisasi dari konsep ajaran Ihsan sebagai puncak dari ajaran etika yang sangat mulia. Ihsan merupakan 
22 | TAZKIR: Jurnal Penelitian Ilmu-ilmu Sosial dan Keislaman

Vol. 03 No. 1 Juni 2017

melaksanakan perbuatan baik yang dapat memberikan kemanfaatan kepada orang lain demi mendapatkan Ridho Allah SWT. Disamping itu, bantuan kemitraan PTPN IV Sosa merupakan implikasi dari ajaran kepemilikan dalam Islam. Allah adalah pemilik mutlaq (haqiqiyah) sedangkan manusia hanya sebatas pemilik sementara (temporer) yang berfungsi sebagai penerima amanah. ${ }^{34}$

Jika dikaitkan dengan perspektif ekonomi Islam PT. Perkebunan Nusantara IV sudah cukup baik dalam melaksanakan tanggungjawabnya melaui program kemitraan dan bina lingkungan (PKBL) dan ini telah sesuai dengan prinsip-prinsip dan nilai Islam yaitu pogram PKBL dapat mensejahterahkan masyarakat yang kurang mampu.

PTPN IV Sosa telah melaksanakan tanggung jawabnya dalam melaksanakan dengan baik bantuan dari segi kesehatan bagi masyarakat sekitar perusahaan. Kegiatan ini sesuai dengan ajaran Islam menetapkan tujuan pokok kehadirannya untuk kemaslahatan bagi umat manusia dengan cara memelihara agama, jiwa, akal, keturunan dan harta. Tiga dari lima maqașid al-syāri'ah diatas berkaitan dengan kesehatan..$^{35}$

Akuntanbilitas Abd' Allah merupakan bentuk pertanggungjawaban yang berhubungan dengan ketundukan syariah. Akuntabilitas Abd' Allah primer merupakan kepatuhan perusahaan melakukan penyucian segala sesuatu yang diterima, diproses maupun didistribusika secara halal. Akuntabilitas Abd' Allah sekunder merupakan kepatuhan perusahaan melakukan penyucian yang diterima, diproses maupun didistribusikan yang bebas riba

Jadi, dapat disimpulkan bahwa implementasi Corporate Social Responsibility (CSR) terhadap Shariah Enterprise Theory (SET) bahwa sebagian besar sudah cukup baik dalam pengimplementasian dari beberapa program. Diantaranya program beasiswa bagi anak yang berprestasi sudah cukup Adil, dan dapat dirasakan manfaat beserta mempunyai mașlahah bagi penerima program beasiswa tersebut. Selanjutnya, dibidang program bencana alam, kesehatan dan dana hibah dalam pengimplementasiannya sudah cukup Adil, dan masyarakat sudah 2007). h. 19

${ }^{34}$ Muhammad Djakfar, Etika Bisnis dalam Perspektif Islam, (Malang: UIN Malang Press,

${ }^{35}$ Zaki Fuad Chalil, Etika Bisnis dalam Islam, (jakarta:Kencana), 2009, h. 128 
merasakan manfaat beserta mașlahah dari program kesehatan tersebut. Walaupun ada beberapa responden yang menyatakan perusahaan masih kurang dalam menjalankan programnya terutama dalam bidang mitra binaan, akan tetapi perusaahaan ini sudah tergolong baik dalam penerapan CSRnya, karena sebagian besar masyarakat bendapat respon positif dengan adanya perusahaan ini ditengah-tengah masyarakat.

Hal ini sejalan dengan penelitian yang dilakukan oleh Dwi Endah Manurung bahwa pada awalnya masyarakat menuntut adanya kewajiban yang harus dikeluarkan perusahaan terhadap masyarakat. Kemudian perusahaan mencanangkan berbagi program kemasyarakatan dan lingkungan dengan baik, sehingga berdampak pada perbaikan berbagai aspek kehidupan, seperti kesehatan, pendidikan dan sebagainya. Dengan demikian, pada penelitian Dwi Endah ini bahwa perusahaan menerapkan program CSR selain karena adanya regulasi pemerintah yang mengatur, ditambah desakan warga dan tuntutan warga yang bersifat mengancam, sehingga perusahaan mendapatkan nilai tambah yakni citra perusahaan yang semakin membaik dimata masyarakat. Berbeda dengan penelitian oleh Muhammad Yasir Yusuf melakukan penelitian penggunaan mașlahah syariah dalam penentuan kebijakan pelaksanaan CSR dapat membantu pengelolah bank syariah untuk menyelesaikan pilihan-pilihan rumit, konflik kepentingan antara stakeholders dan benturan-benturan dalam pelaksanaan program CSR.

\section{KESIMPULAN}

Berdasarkan dari hasil penelitian yang telah penulis kemukakan diatas maka penulis dapat menarik beberapa kesimpulan :

1. Program Corporate Social Responsibility (CSR), PT. Perkebunan Nusantara IV Kec. Sosa bentuk program yang dilaksanakan adalah (1) Pemberian dana pinjaman modal kerja, Penggunaan dana pinjaman dapat dibagi beberapa sektor antara lain: Sektor Industri, Sektor Perdagangan, Sektor Pertanian, Sektor Peternakan, Sektor Perkebunan, Sektor Perikanan, Sektor Jasa Bantuan dana hibah, (2) Pendidikan (memberikan bantuan beasiswa dan memperbaiki gedung-gedung sekolah yang rusak). (3) Kerohanian (perbaikan rumah-rumah ibadah). (4) Infrastruktur atau sarana umum (perbaikan jalan, membantu pengadaan peralatan TK, SD, SMP, dan SMA). (5) Sektor 
24 | TAZKIR: Jurnal Penelitian Ilmu-ilmu Sosial dan Keislaman

Vol. 03 No. 1 Juni 2017

Kesehatan (pemberian bantuan dana untuk pemberian sembako bencana alam, obat-obatan, sunatan massal (6) Pelestarian alam (penghijauan).

2. Implementasi program CSR PT. Perkebunan Nusantara IV Sosa dengan memberikan modal usaha terdapat Mitra Binaan berjumlah 95 kelompok akan tetapi yang aktif di dalamnya kurang lebih 30 Mitra. Pada total dana yang disalurkan adalah senilai Rp. 385 juta sedangkan program bina lingkungan adalah meliputi penyaluran dana kepada msyarakat berupa bantuan bencana alam, pendidikan dan pelatihan, peningkatan kesehatan masyarakat, pengembangan prasana umum, pembangunan sarana ibadah dan pelestarian alam/lingkungan. Realisasi penyaluran dana bina lingkungan bina lingkungan sepanjang tahun 2014 mencapai Rp. 1,4 Milyar. Selain dana yang bersumber dari penyisihan Laba Bersih, PTPN IV juga menganggarkan dana CSR sebagai biaya yang dibebankan kepada perusahaan. Sepanjang tahun 2015, perusahaan telah menyalurkan dana CSR sebesar Rp. 1,90 Milyar dari total dana yang dianggarkan sebesar 4 Milyar.

3. Tinjauan Shariah Enterprise Theory terhadap pelaksanaan program Corporate Social Responsibility (CSR) PT. Perkebunan Nusantara IV Sosa jika dilihat dari segi tujuan, bahwa program ini telah sesuai dengan prinsip dan berbagi Adil, Kemaslahatan dan Rahmatan lil'alaminn karena CSR dalam perspektif Islam merupakan konsekuensi inhern dari ajaran Islam itu sendiri. Tujuan dari syariat Islam (Maqașid al-Syāri'ah) adalah mașlahah sehingga bisnis adalah upaya untuk menciptakan mașlahah, bukan sekedar mencari keuntungan. 


\section{DAFTAR PUSTAKA}

Alqur'anul Karim

Abdus Samad dan M. Kabir Hassan, "The Performance Of Malaysian Islamic Bank During 1984-1997: An Exploratory Study", International Journal of Islamic Financial Services, 2000. Vol. 1 No.3

Ahmad Khaliq. Islamic Ethis in a Changing Environment for Managers, in Abul Hasan M. Sadeq (ed). Ethics in Business and Mnagement: Islamic and Mainstream Approaches. London: Asean Academic Press. 2003.

Al-Ghazali Abu Hamid. Al-Mustafa (Cairo:Al-maktabah Al-Tijariyyah AlKubra). 1534M.

Al-Shatibi, Abu Ishaq.(d.790/1388), (n.d), Al-Muwafaqat fi Usul AlShari'ah.Cairo:AL- Maktabah Al-Tijariyyah Al-Kubra.

Amiruddin dan Zainal Asikin, Pengantar Metode Penelitian Hukum (Jakarta: Raja Grafindo Persada, 2008.

Arafat, Wilson. Good Coreporate Governance. Jakarta: Salemba Empat, 2010.

Arikunto, Suharsimi, Manajemen Penelitian (Jakarta: Rineka Cipta, cet.10, 2009.

Asyhadie, Zaeni. Hukum Bisnis Prinsip dan Pelaksanaannya di Indonesia, Jakarta : PT.RajaGrafindo Persada, 2008 ), Edisi Revisi 3.

Azhar Maksum dan Azizul Kholis, "Analisis Tentang Pentingnya Tanggung Jawab dan Akuntansi Sosial Perusahaan (Corporate Responsibility And Social Accounting): Studi Empiris di Kota Medan", Simposium Nasional Akuntansi VI, Surabaya, 16 - 17 Oktober 2003.

Badroen, Faisal dkk. Etika Bisnis Dalam Islam, Jakarta:Kencana, 2007.

Bobo, Jolius. Tranformasi Ekonomi Rakyat, Jakarta: PT. Pustaka Cidesindo, 2003

Budi, Hendrik Untung, Corporate Social Responsibility, Jakarta: Sinar Grafika Offet, 2009.

Carnoy, Martin dan derek shearer, ekonomic democrary,sharpe inc.1980.

Casson B Maali, \& Napier, Social Reporting by Islamic Banks.Abacus, 201242 (2), 266-289. 
26 | TAZKIR: Jurnal Penelitian Ilmu-ilmu Sosial dan Keislaman

Vol. 03 No. 1 Juni 2017

Chapra, Umar\& Habib Ahmed. Corporate Governance (terjemahan Ikhwan Abidin).Jakarta Timur: Sinar Grafika Offset,2008.

Corporate Social Responsibility Indonesia Newsletter: 2008

Daud, Abi Sulaiman bin Al-'asy'atsu As-sajastaanii, Sunan Abi Daud, Bairut : DarAlfkru, 1414H- 1994 M.

Dima Jamali, "A Stakeholder Approach to Corporate Social Responsibility: A Fresh Perspective into Theory and Practice", Journal of Business Ethnics, 2008.82:213-231.

Dusuki, Asyraf Wajidi and Dar, Humayan, Stakeholder's Perceptions of Corporate Social Responsibility of Islamic Banks: Evidence from Malaysian Economy. The $6^{\text {th }}$ International Confrence of Islamic Economic and Finance, 2005.

Maqasid Al-Shariah, Maslahah, and Corporate Social Responsibility.The American Journal of Islamic social sciences, 2007.

Dusuki dkk. Maqasid Al-Shariah, Maslahah, and Corporate Social Responsibility. The American Journal of Islamic social sciences, 2007.

Dwi Endah Mira Manurung. Analisis Penerapan Corporate Social Responsibility (CSR) pada PT. Perkebunan Nusantara IV-Medan. Tesis Depok, Universitas Indonesia, 2012

Edi Suharto, Pekerjaan Sosial Di Dunia Industri Memperkuat Tanggung Jawab Sosial Perushaan,Bandung: PT Refika Aditama, 2007.

Eklington, Jhon. Penerapan Corporate Social Responsibility.Jakarta: Salemba 4,2007.

Ernawan, Erni R. Business Ethics. Bandung: Alfabeta, 2007.

Farook, Sayd and Lanis, Roman.Banking On Islam? Determinants of Corporate Social Responsibility Disclosure.The $6^{\text {th }}$ International Confrence on Islamic Economic and Finance, 2005.

Hartanti, Dwi. "Islam Dan Tanggung Jawab Sosial : Studi Perbandingan Pengungkapan Berdasarkan Global Reporting Initiative Indeks Dan Islamic Social Reporting Indeks", dalam skripsi, Jurnal Ilmu Syariah dan Hukum vol. 46 no. 2 Desember 2010

Iqbal, Zamir. Pengantar Keuangan Islam (Teori \& Praktik). Jakarta:Kencana, 2008.

Jogianto H.M, Metodologi Penelitian Bisnis: Salah Kaprah dan Pengalamanpengalaman (Yogyakarta: BPFE-Yogyakarta, cet.2, 2009 
Jolius Bobo, Tranformasi Ekonomi Rakyat, Jakarta: PT. Pustaka Cidesindo, 2003.

Kebersamaan dan Asas Kekeluargaan, Jakarta:UNJ Press,2004.

Leksono, Sonny, Penelitian Kualitatif Ilmu Ekonomi dari Metodologi Ke Metode, Jakarta: PT Raja Grafindo Persada, Jakarta, 2013, Cetakan Ke-1

M Umer Chapra. The Islamic Vision of Development in The Light of Maqasid AlShari'ah. Jeddah: Islamic Research and Training Institute Islamic Depelopment Bank. 2007.

M.B. Hendrie Anto dan Dwi Retno Astuti, “Persepsi Stakeholder Terhadap Pelaksanaan Corporate Social Responsibility Kasus Pada Bank Syariah di DIY", Sinergi: Kajian Bisnis dan Manajemen, Vol. 10 No.1, Januari 2008.

Machfoedz, Mahmud. Pengantar Bisnis Modern, Yogyakarta: Andi, 2007, Edisi. Ke-1.

Mahmud, Peter Marzuki. Penelitian Hukum. Surabaya: Kencana, 2002.

Maignan, I., Ferrell, O. C., \& Hult, G. T. 2004. Corporate citizenship: Cultural antecedents and business benefits. Journal of the Academy of Marketing Science, 27(4): 455-469

Manuel Castelo Branco dan Lủcia Lima Rodrigues, "Corporate Social Responsibility and Resource- Based Perspectives" Journal of Business Ethics, 2006.69:111132

Martono, Pemberdayaan Studi Kelayan Ekonomi. Bandung: Rajawali Pers, 2009.

Meutia, Inten.Menata Pengungkapan CSR di Bank Islam (Suatu Pendekatan Kritis), Jakarta: Citra Pustaka Indonesia, 2010.

Mohammed, J.A. An Islamic Perspektive of Corporate Social Responsibility.The Global Conference on Business, economics and Social Scienes Research (GBSR), 2013.

Muh. Ghafur Wibowo, Potret Perbankan Syariah Terkini: Kajian Kritis Perkembangan Perbankan Syariah Terkini. Yogyakarta: Biruni Press, 2007.

Muhammad dan Lukman Fauroni, Visi Al-Quran tentang Etika dan Bisnis, Jakarta: Salemba Diniyah, 2002.

Muhammad, Prinsip-prinsip Ekonomi Islam. Yogyakarta: Graha Ilmu, 2007.

Muhammd Yasir Yusuf. Aplikasi CSR pada Bank Syariah: suatu pendekatan maṣlaḥah dan Maqasid syariah. EKSIBISI, Vol 4, No 2, Juni 2010. 
28 | TAZKIR: Jurnal Penelitian Ilmu-ilmu Sosial dan Keislaman

Vol. 03 No. 1 Juni 2017

Muqorobin, Masyudi. Fikih Tata Kelola Organisasi Laba: Sebuah Pengantar Universitas Muhammadiyah: Purwekerto, 2011.

Naqvi, Haidar. Menggagas Ekonomi Islam, Yogyakarta: Pustaka Pelajar, 2003.

Norman K. Denzin dan Yvonna S. Lincoln, Hand Book Of Qualitative Research, Terj. Dariyatno dkk.Yogyakarta: Pustaka Pelajar, 2009.

Nuruddin, Amiur \&Veithzal Rivai, Islamic Business and Economic Ethic. Jakarta : Bumi Aksara, 2009.

Purwitasari, Fadilla "Analisis Pelaporan Corporate Social Responsibility Perbankan SyariahDalam Perspektif Shariah Enterprise Theory : Studi Kasus Pada Laporan TahunanBank Syariah Mandiri Dan Bank Muamalat Indonesia" dalam Skripsi vol. 61 no. 1, Juni 2011.

Riky \& Evi, "Islamic Social Reporting Index Sebagai Model Pengukuran Kinerja Sosial Perbankan Syariah (Studi Komparasi Indonesia dan Malaysia " dalam Artikel Syariah vol. 24, 2016.

Rivai,Viethzal. Islamic Human Capital, (Jakarta : Rajawali Pers,2009), Edisi. Ke-1.

Rudito, Bambang \& Melia Famiola, Corporate Social Responsibility, Bandung: Rekaya Sains, 2013

Rusdin. Pasar Modal. Jakarta: Kencana, 2010.

Sholihin, Ismail. Coporate Social Responsibility. Jakarta: Kencana, 2010.

Sri-Edi, Swasono, kembali ke Pasal 33 UUD 1945 Menolak Neoliberlisme, Jakarta: Yayasan Hatta, 2004.

Suhandari M. Putri. Schema CSR. Kompas edisi 4 Agustus 2007.

Surya, Indra \& Ivan. Penerapan Good Corporate Governance. Jakarta: Kencana, 2008.

Suswanto, Pembangunan Ekonomi Bisnis, Jakarta: Kencana, 2010.

Sutomo, Perusahaan di Indonesia, Jakarta: Rajawali Perss, 2010.

Sutrisno, Etika Bisnis Dalam Islam. Jakarta: 2009.

Teguh, Mahmud. Ekonomi Industri, (Jakarta : Rajawali Pers,2010), Edisi. Ke-1. 
Widiyanti, Novi Wulandari., Corporate Governance dalam Pandangan Islam: Sebuah Konsep Altertantif dalam Penerapan Good Corporate Governance. Universitas Jember: 2009.

Widjaja, Gunawan \& Yeremia Ardi Pratama.Risiko Hukum \& Bisnis Perusahaan Tanpa CSR. Jakarta: Forum Sahabat, 2008.

Yusuf, Wibisono. Membedah Konsep dan Aplikasi CSR. Gresik: Fascho Publishing, 2007.

Yusuf, Yasir. Aplikasi CSR pada Bank Syariah: Suatu Pendekatan Maslahah dan Maqashid Syariah. EKSIBISI, Vol 4, No 2, Juni 2010. 98-115 
30 | TAZKIR: Jurnal Penelitian Ilmu-ilmu Sosial dan Keislaman Vol. 03 No. 1 Juni 2017

Analisis Kesesuaian Jurnal Perkuliahan Dosen dengan Silabus Pembelajaran TBI 